\title{
Transcranial pulsed Doppler ultrasound findings in brain stem death
}

\author{
F J KIRKHAM,* S D LEVIN,* T S PADAYACHEE, $\dagger$ M C KYME,* B G R NEVILLE,* \\ R G GOSLING $\dagger$
}

From the Departments of Paediatrics* and Radiological Sciences, $\dagger$ Guy's Hospital, London UK

SUMMARY Data are presented from transcranial insonation of the middle cerebral artery (MCA) performed at intervals in 23 unconscious children for whom the outcome was subsequently poor. Once an MCA signal had been observed over a 30 minute period with time averaged velocity less than $10 \mathrm{~cm} \mathrm{~s}^{-1}$ and/or a direction of flow index, DFI, defined as 1 minus the ratio of reverse to forward flow of less than $0 \cdot 8$, recovery to forward flow throughout diastole was never observed and no patient recovered brain stem reflexes. Recovery of forward flow in diastole, and of brain stem function, was seen in cases with time averaged MCA velocity in the range 10 to $25 \mathrm{~cm} \mathrm{~s}^{-1}$ and with reverse flow but a DFI of greater than 0.8 for short periods of time. All but one of the 13 children fulfilling clinical criteria for brain stem death had MCA signals with time averaged velocity of less than $10 \mathrm{~cm} / \mathrm{s}$ and DFI of less than $0 \cdot 8$. This type of signal was not observed in five children who were left in a persistent vegetative state.

Clinical criteria for the diagnosis of brain death are now established ${ }^{1-3}$ and have been shown to be reliable, ${ }^{45}$ provided that the cause has been ascertained, the patient's temperature is above $35^{\circ} \mathrm{C}$ and there are no drugs present. Although there is no evidence of a difference from adults, there is less experience with the criteria in children. ${ }^{67}$ It has therefore been suggested that for this age group the clinical diagnosis should be confirmed with tests such as cerebral angiography or cerebral blood flow (CBF) studies. $^{8}$

Paediatric neurointensive care has developed very rapidly recently and an improvement in prognosis has been reported for children with head injury, ${ }^{9}$ neardrowning, ${ }^{10}$ and Reye's syndrome. ${ }^{11}$ Ideally, aggressive treatment should be used only when there is a chance of good recovery. A simple screening test for early identification of children with irreversible brain damage would therefore be useful.

A technique for obtaining Doppler signals from the basal cerebral arteries was described by Aaslid in 1982. ${ }^{12}$ The vessels are insonated transcranially using a low carrier frequency of $2 \mathrm{MHz}$ which penetrates

Address for reprint requests: Dr F J Kirkham, Department of Paediatrics, Guy's Hospital, St Thomas Street, London SE1 9RT, UK.

Received 9 December 1986 and in revised form 26 March 1987. Accepted 2 April 1987 bone sufficiently to allow back scattered Doppler signals to be obtained. Middle cerebral artery (MCA) velocity may be reliably ${ }^{13}$ and reproducibly ${ }^{14}$ measured and appears to be a useful index of CBF. ${ }^{15}$

Several authors have demonstrated abnormal Doppler waveforms in the extracranial cerebral arteries of clinically brain dead patients. In 10 adults, Yoneda ${ }^{16}$ reported that reverse flow was always seen in the common carotid artery in patients with an isoelectric EEG and non-filling of the intracerebral arteries on arteriography; Despland and De Crousaz ${ }^{17}$ observed a similar signal in the common carotid in six clinically brain dead individuals. Diagnostic accuracy may be improved by the use of computerised waveform analysis. ${ }^{18}$ However, demonstration that recovery is possible despite the finding of reverse flow in the common carotid artery ${ }^{19}$ means that this is not a useful confirmatory test of brain death. Low velocity and reverse flow have been demonstrated in the internal carotid and vertebral arteries of brain dead patients. ${ }^{20}$ False positives have not been reported, but the vessels may be difficult to insonate, particularly when the signal is small. The only previous report of the findings in the intracerebral arteries was by McMenamin and Volpe ${ }^{21}$ who described the very abnormal anterior cerebral artery waveforms, obtained throught the fontanelle, in six brain dead infants. 
In this paper we report the use of transcranial pulsed Doppler ultrasound to measure MCA blood velocity in 23 unconscious children of whom 17 had absent brain stem reflexes, while six were deeply unconscious but with some preservation of brain stem function.

\section{Patients and methods}

The patients described in this paper formed part of a larger study using transcranial pulsed Doppler ultrasound in 80 unconscious children. Twenty three, with very bad outcome, are presented in table 1 . The outcome for the remaining 57 was better, although many were left handicapped. The mean age of this group was $4 \cdot 8$ years (range: 3 days-14 years); there were 12 boys and 11 girls.

Clinical examination was performed regularly, recording sedating drugs. Continuous EEG monitoring was performed using a cerebral function analysing monitor ${ }^{22}$ (CFAM Medaid) in 22, and a three channel tape system ${ }^{23}$ (Medilog, Oxford Medical) in one. EEG was graded on a scoring system modified from the work of Pampiglione and Harden: ${ }^{24}$ 5 Normal for age, 4 High amplitude diffuse slowing, 3 Continuous seizure, 2 Very low amplitude, 1 Burst suppression, 0 Isoelectric.

Blood pressure was monitored continuously in all and mean arterial pressure (MAP) calculated. Intracranial pressure (ICP) was monitored in nine patients, in six with a subdural screw and in three with an intraventricular catheter, and cerebral perfusion pressure, $\mathrm{CPP}=\mathrm{MAP}-\mathrm{ICP}$, was calculated frequently.
Transcranial ultrasound studies were performed at the bedside using a $2 \mathrm{MHz}$ directional pulsed Doppler velocimeter (Alfred, Vingmed). The signals were displayed in a realtime sonagram format on a two channel spectral analyser (Doptek) and were simultaneously recorded onto stereo cassette tape. The transducer was placed on the temporal bone just above the zygomatic arch. Transducer position, inclination and the Doppler sample depth were adjusted until the optimum signal was obtained towards the probe at an appropriate depth for insonation of the MCA.${ }^{13}$ Recordings were made over a period of at least 30 minutes. If signals attributable to the MCA could not be found by three independent observers with experience of the technique, the signal was deemed to be absent. Serial studies were performed in 21 children.

The blood velocity sonagrams were played out onto light sensitive paper (Kodak, Linagraph 1801) to form a permanent record for off-line analysis. The time averaged maximum Doppler frequency was calculated using a digitising pad (Summagraphics Ltd) and dedicated microprocessor (Autograph). Waveforms over three cardiac cycles were analysed at each sample point and the mean was taken. Assuming the angle of insonation to be zero, the velocity, $v$, was calculated from the Doppler equation:-

$$
\mathrm{f}=\frac{2 \mathrm{vfi} \operatorname{Cos} \theta}{\mathrm{c}}
$$

where $f$ is the frequency of the maximum Doppler shift, $f$ is the incident ultrasound frequency, and $\mathrm{c}$ is the speed of ultrasound in human soft tissue $\left(1540 \mathrm{~m} / \mathrm{s}^{-1}\right)$

A direction of flow index (DFI) was defined as:-

$$
\mathrm{DFI}=1-\mathrm{R} / \mathrm{F}
$$

\begin{tabular}{|c|c|c|c|c|c|}
\hline Patient No & Age & Cause of coma & $\begin{array}{l}\text { Duration } \\
\text { of coma (hours) }\end{array}$ & $\begin{array}{l}\text { Sedative } \\
\text { drug treatment }\end{array}$ & Outcome \\
\hline 1 & $4 \mathrm{yr}$ & Cardiac arrest & 49 & - & 1 \\
\hline 2 & $9 \mathrm{~m}$ & Cardiac arrest & 94 & Phenobarbitone & 1 \\
\hline 3 & $2 \mathrm{yr}$ & Cardiac arrest & 77 & Ethomidate & 1 \\
\hline 4 & $14 \mathrm{yr}$ & Cardiac arrest & 22 & - & 1 \\
\hline 5 & $4 \mathrm{yr}$ & Cardiac arrest & 38 & $\cdots$ & 1 \\
\hline 6 & $3 \mathrm{~m}$ & Cardiac arrest & 44 & - & 1 \\
\hline 7 & $17 \mathrm{~m}$ & Cardiac arrest & 22 & - & $i$ \\
\hline 8 & $7 \mathrm{yr}$ & OTC deficiency & 76 & & 1 \\
\hline 9 & $9 \mathrm{yr}$ & Head injury & 38 & - & 1 \\
\hline 10 & $8 \mathrm{yr}$ & Head injury & 28 & - & $i$ \\
\hline 11 & $4 \mathrm{yr}$ & Head injury & 118 & - & 1 \\
\hline 12 & $4 d$ & Birth asphyxia & 100 & - & $i$ \\
\hline 13 & $6 \mathrm{yr}$ & Encephalitis & 655 & - & 1 \\
\hline 14 & $12 \mathrm{yr}$ & Polyarteritis & 107 & Thiopentone & 2 \\
\hline 15 & $2 \mathrm{yr}$ & Haemolytic, uraemic & 83 & & 2 \\
\hline 16 & $10 \mathrm{yr}$ & Cardiac arrest & 168 & Thiopentone & 3 \\
\hline 17 & $21 \mathrm{~m}$ & Head injury & 58 & & 4 \\
\hline 18 & $5 \mathrm{~m}$ & Meningitis & 44 & & 5 \\
\hline 19 & $10 \mathrm{~m}$ & Cardiac arrest & 825 & - & 6 \\
\hline 20 & $7 \mathrm{yr}$ & Cardiac arrest & 468 & - & 6 \\
\hline 21 & $10 \mathrm{~m}$ & Cardiac arrest & 200 & & 6 \\
\hline 22 & $6 \mathrm{~m}$ & Cardiac arrest & 116 & $\ldots$ & 6 \\
\hline 23 & $14 \mathrm{yr}$ & Cardiac arrest & 573 & - & 6 \\
\hline
\end{tabular}

Table 1 Patients

Outcome:

1 Brain death, ventilation discontinued.

2 Fulfilled criteria for brain death; cardiac death before 2 nd examination.

3 No evidence of brain stem function but drug levels precluded diagnosis of brain death. Cardiac death.

4 No evidence of brain stem function, but hypothermia precluded diagnosis of brain death. Cardiac death

5 Only evidence of brain stem function was slight respiratory effort. Cardiac death.

6 Vegetative state. 

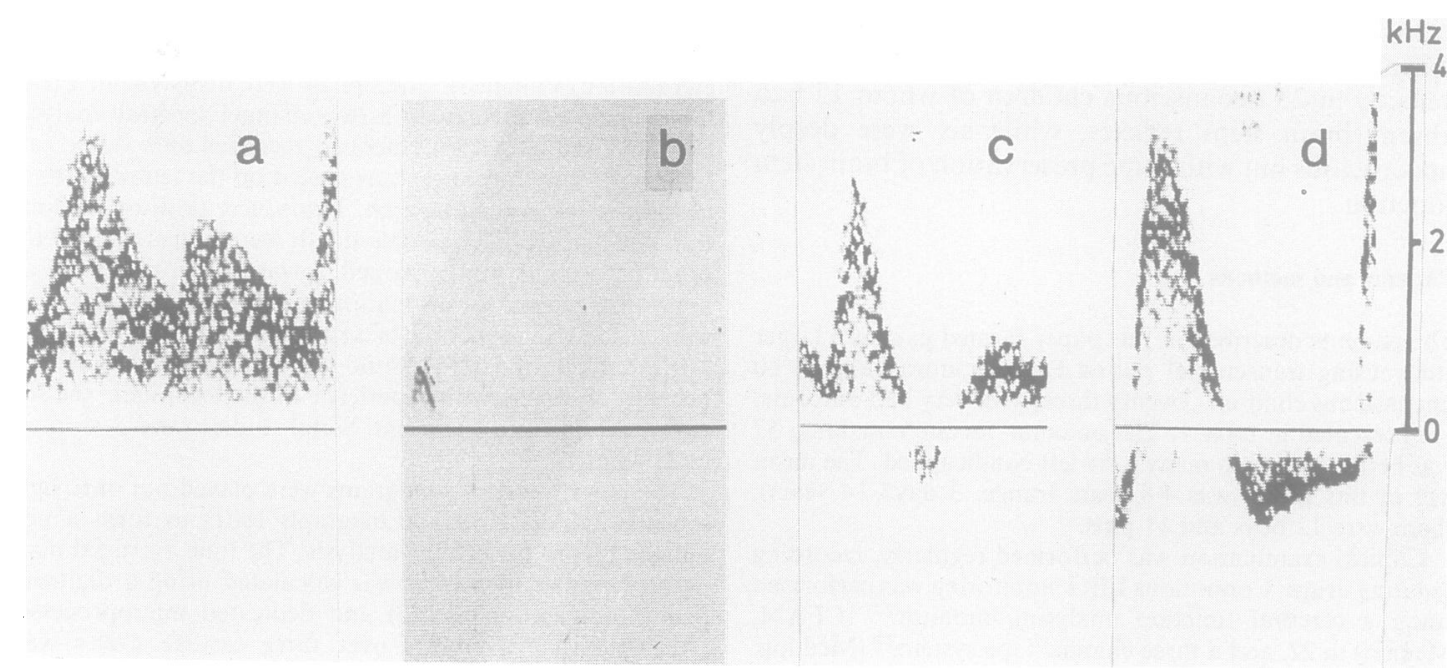

Fig Samples of middle cerebral artery (MCA) sonagrams observed (a) Sonagram with forward flow throughout diastole, $M C A$ velocity $55.2 \mathrm{~cm} / \mathrm{s}$, direction of flow index (DFI) 1.00 (b) Sonagram with no flow in diastole, MCA velocity $2.4 \mathrm{~cm} / \mathrm{s}$, DFI 1.00 (c) Sonagram with small amount of reverse flow in diastole, MCA velocity $24.8 \mathrm{~cm} / \mathrm{s}$, DFI 0.88 (d) Sonagram with reverse flow throughout diastole, MCA velocity $2.3 \mathrm{~cm} / \mathrm{s}$, DFI 0.57 .

where $R$ was the area under the maximum velocity envelope of the reverse flow part of the sonagram and $F$ was the area under the forward flow velocity envelope. The areas $R$ and $F$ were calculated from the permanent record using the digitising pad. A value for DFI of zero therefore indicated that the areas $R$ and $F$ were equal and there was no net forward flow. A value of 1 indicated forward flow only, and values below 1 indicated a degree of reverse flow. A negative value for DFI implied that the area of reverse flow was greater than that of forward flow.

Clinical confirmation of brain stem death was performed by two consultants using the $\mathrm{UK}^{3}$ criteria after all sedating agents had been withdrawn. Cerebral arteriograms were performed in two children.

\section{Results}

\section{Transcranial ultrasound}

In 17 of the 23 children with bad outcome, reverse flow was observed in diastole at some stage during the course of their illness (table $2 a, b, c$; fig c, d). A normal signal with forward flow in diastole was never seen subsequently if the DFI was less than $+0 \cdot 8$, and the MCA velocity, time averaged over the cardiac cycle, was less than $10 \mathrm{~cm} \mathrm{~s}^{-1}$ over the 30 minute period (patients 1-12, 14, 16, 17; fig d). In five (Patients 4, 5, 7, 9, 17), this signal was seen soon after admission, while in the remainder, a signal with forward flow throughout diastole was observed initially and the reverse flow signal appeared after subsequent clinical or EEG deterioration. In four, no signal could be obtained at all at the final examination. Of this group, 12 fulfilled clinical criteria for brain death on two occasions and ventilation was therefore discontinued (table 1). One (Patient 14) was clinically brain dead on one occasion, but became asystolic before the second examination could be performed. In a further two, there was no evidence of brain stem function, but high barbiturate levels (Patient 16) or hypothermia (Patient 17) precluded the diagnosis of brain stem death. Both became spontaneously asystolic despite intensive care.

In one child (Patient 15), a very low velocity signal, with no flow in diastole, was observed (DFI therefore 1) (fig b, table 2c). She fulfilled clinical criteria for brain death on one occasion but died before the second examination. A similar low velocity signal, with no flow in diastole, was seen on the left side in Patient 6 , while the typical reverse flow pattern was seen on the right. Patient 13 was the only one to have diastolic forward flow in the MCA at the time brain stem death was confirmed clinically (table $2 c$ ). This was observed on one side only; on the other, no signal could be obtained. During physiotherapy a few days earlier, a small area of reverse flow had been noted in the MCA sonagram (DFI $>0.8$, table $2 \mathrm{~b}$ ).

In four children (Nos 3,13, 18, 19), a signal with reverse flow in diastole was observed over periods of 10-90 minutes, with a DFI of greater than $0 \cdot 8$, and MCA velocity $>10 \mathrm{~cm} \mathrm{~s}^{-1}$ (table $2 \mathrm{a}, \mathrm{b}, \mathrm{c}$; fig c). Recovery to forward flow in diastole was observed in three (Nos 3,13,19), but two subsequently died brain deaths (Nos 3, 13), and the third (No 19) remained in 
Table 2a

Findings on admission to study

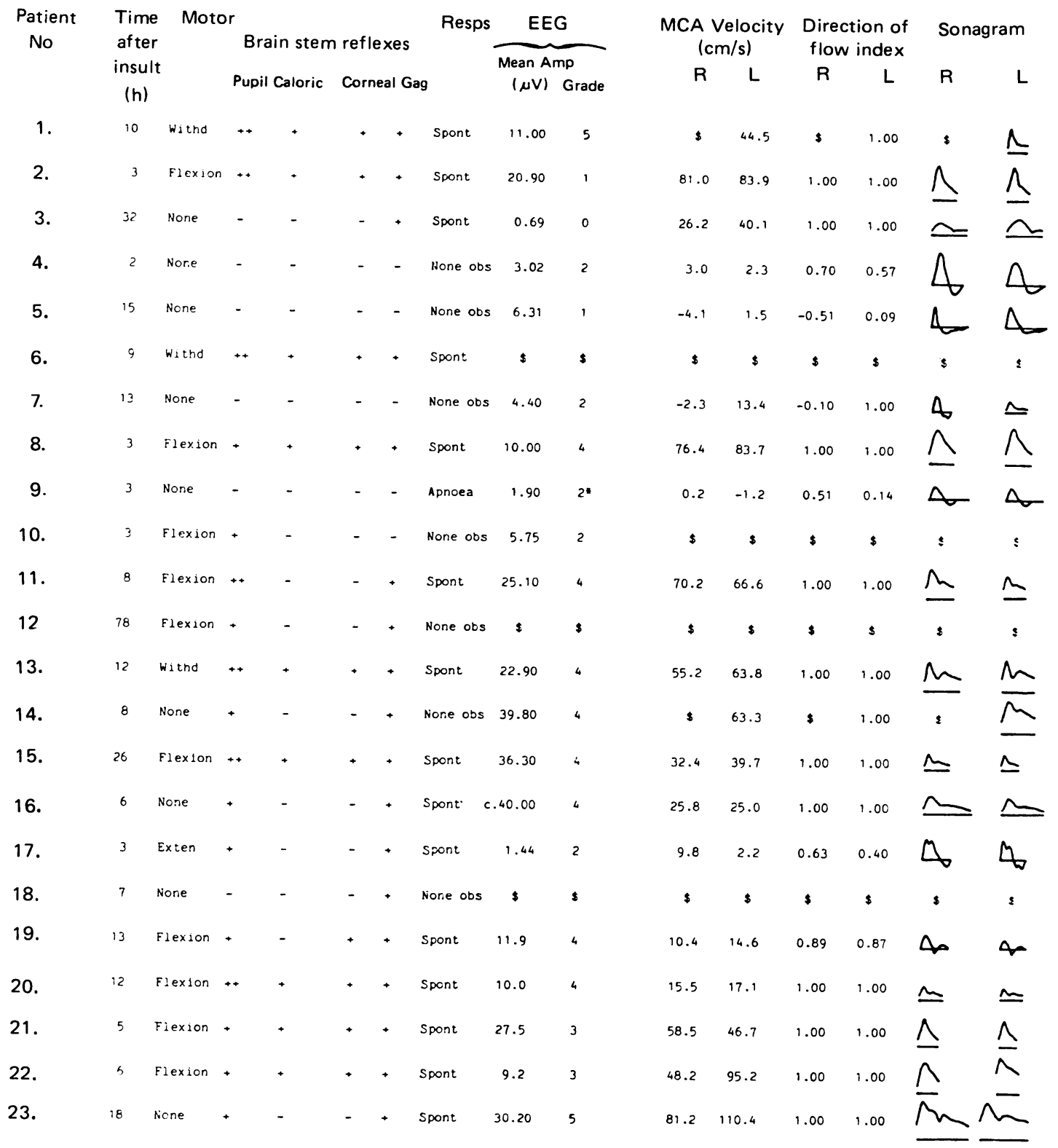


Table 2b

Intermediate examinations

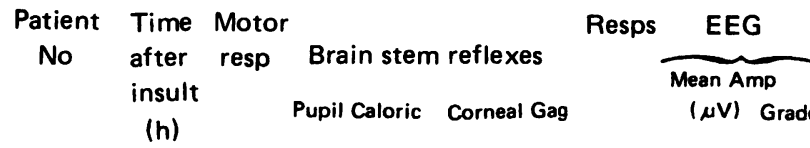

1.

2. 60 Weak + + + Spont 5.252

3.

$\begin{array}{lllllllll}38 & \text { None } & - & - & - & - & \text { None obs. } & 0.91 & 0 \\ 42 & \text { None } & - & - & - & - & & & \\ & & & & & & & & \\ 60 & \text { None obs. } & 0.91 & 0\end{array}$

4. 7 None $\quad 7 \quad-\quad-\quad-A p n o e a \quad 1.58 \quad 2$

5. 16 None $\quad$ - $\quad$ - $\quad$ - $\quad$ - Apnoea $1.32 \quad 1$

6.

$$
7
$$

8

9.

10.

11. $98 \quad$ None $\quad$ - $\quad$ - $\quad$ - $\quad$ - Apnoea $0.91 \quad 0$

12. 87 None $\quad$ - $\quad$ - None obs. \& 3

13. 590 None - $\quad$ - $\quad$ - Rone obs. $36.30 \quad 4$

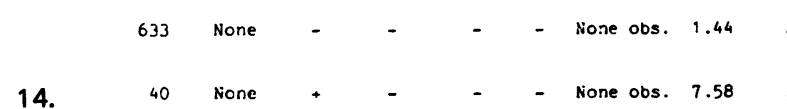

15. 60 None - $\quad$ - $\quad$ - None obs. $0.03 \quad 0$

16. 50 None - $\quad$ - $\quad$ - lione obs. $0 \quad 0$

17. 9 None - $\quad$ - $\quad$ - None obs. 1.10

18. 9 None $\quad$ - $\quad$ - $\quad$ - $\quad$ - Sone obs. $0.83 \quad 0$

19. 22 Flexion + - + + tione obs. 25.10 4

20. 89 Flexion +* + + + Spont 2.292

21. 19 flexion + + + * : *one obs. 1.322

22. 18 Exten. + + + + lione obs. $1.74 \quad 2$

23. 168 Exten. + $+\quad+\quad+$ Spont $4.79 \quad 1$

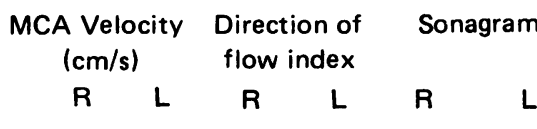

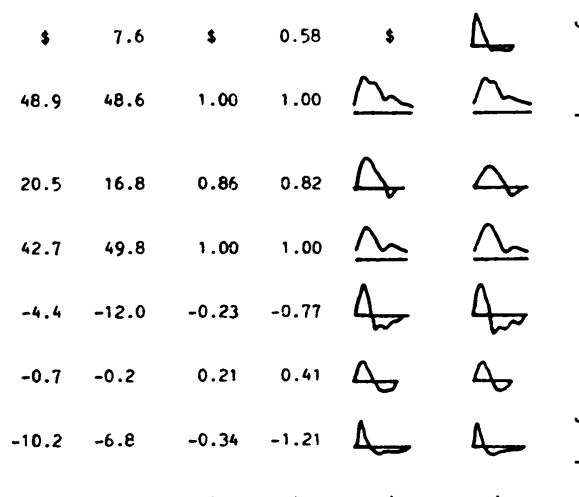

s s s

$-2.3+-0.40 \leqslant 4$

$19.9 \$ 1.00 \times \mathrm{m}$

$\begin{array}{lllll}-2.5 & 2.4 & 0.28 & 0.48 \quad 4\end{array}$

$4 \quad \stackrel{\frac{\rho}{10}}{\circ}$

\$ \$ s

$\begin{array}{lllll}9.7 & 6.0 & 0.61 & 0.63 \quad \Delta\end{array}$

$\begin{array}{lllll}1.0 & 1.4 & 0.38 & 0.27 \quad \bigsqcup_{b}\end{array}$

$\begin{array}{lllll}1.2 & 0.3 & 0.15 & 0.23\end{array}$

\$ 24.8 \$ 0.88 \$

\& $\$$

$\$ 32.3 \$ 1.00 \$ \underline{\Lambda}$

$\$$ \$ \$ s

$\begin{array}{lllll}-1.8 & -9.9 & -0.86 & -1.67 \quad \square\end{array}$

$\begin{array}{lllll}1.9 & -3.6 & 0.40 & 0.06 \quad \square\end{array}$

No sig. 9.3 No sig. 1.00 No sig.

$27.9 \quad 30.6 \quad 1.00 \quad 1.00 \quad M \quad M$

-

$\Delta \quad \stackrel{\frac{0}{2}}{\frac{0}{3}}$

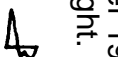

Ac

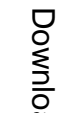

$\frac{1}{8}$

$\begin{array}{llllll}109.2 & 100.4 & 1.00 & 1.00 & M & N \\ 48.7 & 41.8 & 1.00 & 1.00 & \Omega & \Omega\end{array}$

西 
Table 2c

Final examination

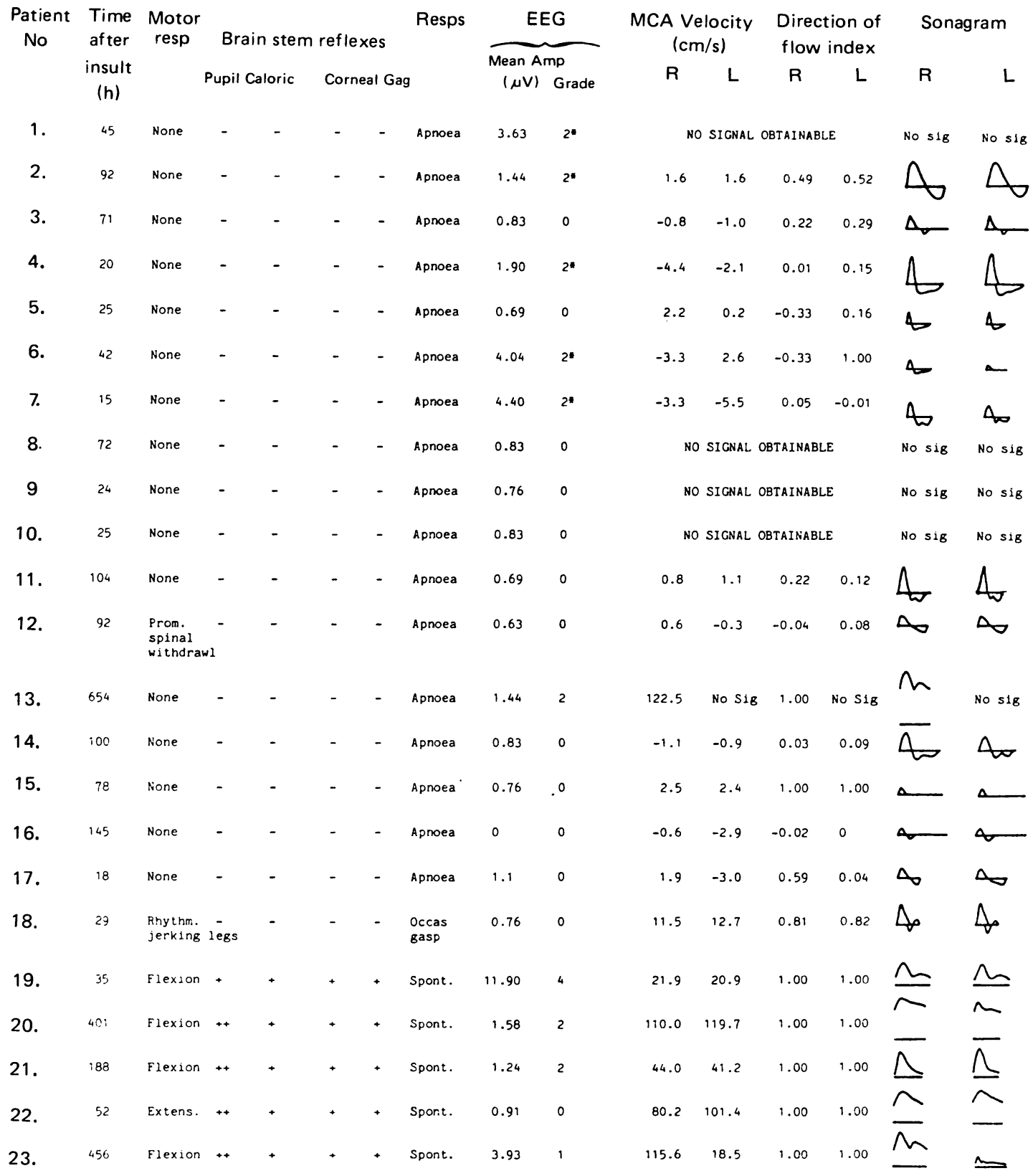


Table 3 Mean arterial pressure, intracranial pressure, cerebral perfusion pressure when reverse flow first seen or during secondary deterioration

\begin{tabular}{|c|c|c|c|c|c|c|c|}
\hline \multirow[b]{2}{*}{ Patient No } & \multirow[b]{2}{*}{ Outcome } & \multirow[b]{2}{*}{$\begin{array}{l}R M C A \\
\text { velocity (cms 1) }\end{array}$} & \multicolumn{5}{|c|}{ At deterioration } \\
\hline & & & $D F I R$ & $\begin{array}{l}M A P \\
(m m H g)\end{array}$ & $\begin{array}{l}I C P \\
(m m I I g)\end{array}$ & $\begin{array}{l}(P P P \\
(m m I g)\end{array}$ & Comments \\
\hline 2 & 1 & $1 \cdot 6$ & 0.52 & 63 & - & - & $\begin{array}{l}\text { Surgical decomp CPP prev } \\
<30 \mathrm{~mm} \mathrm{Hg}\end{array}$ \\
\hline 8 & 1 & $2 \cdot 4$ & 0.48 & 53 & (8) & $(45)$ & $\begin{array}{l}\text { ICP mon probably not func } \\
\text { severe cerebral oedema } \\
\text { at necropsy }\end{array}$ \\
\hline 11 & 1 & $1 \cdot 4$ & $0 \cdot 27$ & 88 & 84 & 4 & \\
\hline 12 & $i$ & -0.9 & $0 \cdot 23$ & 66 & 64 & 2 & \\
\hline 13 & $i$ & $42 \cdot 0$ & 0.88 & 58 & 8 & 50 & \\
\hline 14 & 3 & $-2 \cdot 9$ & 0.09 & 57 & 52 & 5 & \\
\hline 19 & 6 & $14 \cdot 6$ & 0.87 & 55 & & & ICP mon inserted later \\
\hline 20 & 6 & $100 \cdot 4$ & 1.00 & 62 & 20 & 42 & - \\
\hline 21 & 6 & $41 \cdot 2$ & $1 \cdot 00$ & 48 & 4 & 44 & - \\
\hline
\end{tabular}

a vegetative state and died later. The only evidence of brain stem function in the fourth was slight respiratory effort, and he became spontancously asystolic soon afterwards.

In four children (Nos 20, 21, 22, 23), there was evidence of clinical and EEG deterioration but reverse flow in diastole was never observed in the sonagrams obtained. These children showed evidence of persisting brain stem function, as did Patient 19, in whom reverse flow was observed in diastole (DFI $>0.8, \mathrm{~V}$ $>10 \mathrm{~cm} / \mathrm{s}$ ) which subsequently disappeared. None recovered consciousness to better than vegetative state and all subsequently died.

\section{Relationship between DFI and ICP (table 3)}

In three of the patients with a DFI of $<0.8$ and MCA velocity $<10 \mathrm{~cm} \mathrm{~s}^{-1}$ (Nos 11, 12, 14), ICP was close to MAP with CPP $<5 \mathrm{~mm} \mathrm{Hg}$. In a fourth, Patient 8 , ICP measured with a subdural screw was much less than MAP, but at necropsy the brain was very swollen and the screw may have been blocked. In Patient 13, the ICP was $8 \mathrm{~mm} \mathrm{Hg}$ with a CPP of $50 \mathrm{~mm} \mathrm{Hg}$, when a sonagram with a DFI of 0.88 was observed. In Patient 2 ICP was monitored but he was surgically decompressed before the reverse flow signal was seen. ICP was monitored and was low after recovery to forward flow in Patient 19, but CSF was released at apparent high pressure on insertion of the intraventricular catheter. CPP was 42 and $44 \mathrm{~mm} \mathrm{Hg}$ during EEG deterioration in Patients 20 and 21 in whom reverse flow in diastole was not observed.

\section{Correlation with carotid arteriography}

Arteriograms were obtained in Patients 8 and 22 . Patient 8, a seven year old boy with ornithine transcarbamylase (OTC) deficiency, had a rapidly deteriorating clinical course with low MCA velocity at 52 hours, and reverse flow bilaterally at 67 hours (table 2b). At 72 hours no signal could be obtained (table 2c). An arteriogram was performed and this confirmed non-filling of the intracranial cerebral vessels.

Patient 23, a 14 year old girl, remained in deep coma for several weeks with preserved brain stem function and a burst suppression pattern EEG. On day 19, the MCA Doppler time averaged velocity waso $155.6 \mathrm{~cm} \mathrm{~s}^{-1}$ on the right and $18.5 \mathrm{~cm} \mathrm{~s}^{-1}$ on the lef (table 2c). There was no evidence of reverse flow inn either MCA. The arteriogram showed immediate filling of the cerebrovascular circulation bilaterally.

\section{Discussion}

Brain stem death may be diagnosed clinically in some? patients, for example, with severe head injury, soon after admission to hospital. However, once sedation, paralysis and other aspects of intensive care have been instituted, clinical assessment is not possible without withdrawal of parts of the therapy which may be of benefit to the patient with potential for survival. It is particularly important that treatment of intracranial hypertension is maintained unless the diagnosis of brain death is certain.

The EEG has been advocated as a confirmatory test of the cessation of cerebral function ${ }^{25}$ but may be isoelectric in the presence of continuing brain stem function, ${ }^{26}$ or may persist in the absence of brain stem function. ${ }^{27}$ The latter phenomenon has been particularly common in children. ${ }^{28}$ Persistence of very low amplitude EEG activity has led to prolonged periods of ventilation in some patients with no evidence of brain stem function. In our series, at the final examination, the patients who fulfilled clinical criteria for brain death had isoelectic cerebral function monitor tracings. However, in several the trace was obscured by ECG artefact and, in some, the tracing 
could not be regarded as reliable at an earlier stage because of the effects of sedation. An isoelectric EEG has never been a prerequisite for the diagnosis of brain death in the UK and has latterly become less important in the USA.

When cerebral function fails completely, CBF ceases. $^{29}$ This may be demonstrated arteriographically, ${ }^{30}{ }^{31}$ but there are substantial hazards involved for patients who may recover. ${ }^{32}$ A noninvasive, portable method of screening for presence or absence of cerebral blood flow would therefore be useful. The radioisotope bolus technique ${ }^{33}$ and isotope angiography ${ }^{34}$ fulfil these requirements, but because of the dose of radioactivity, may not be repeated frequently. There are clear advantages in using a Doppler technique for screening if it can be shown to be reliable.

In our series, all children with substantial diastolic reverse flow (DFI $<0.8$ ) in the MCA, with time averaged velocity $<10 \mathrm{~cm} \mathrm{~s}^{-1}$ over a 30 minute period, died without recovering either brain stem function or diastolic forward flow in the MCA. Spontaneous asystole occurred in a few, but in the majority the ventilator was turned off when the UK criteria had been fulfilled on two occasions. Although the proportion of children studied in most clinical series has been small, there is no evidence that recovery may occur in children, outside the neonatal period, in whom brain stem reflexes are consistently absent. The Doppler criteria correlated well with the clinical findings in this series, and there were no false positives, which is particularly important in this context. Four children, with MCA velocity between 10 and $25 \mathrm{~cm} / \mathrm{s}$ and a small area of diastolic reverse flow (DFI $>0.8$ ) over a short period of time, had evidence of brain stem function after this observation, but all subsequently died, and this may therefore have represented an ischaemic insult. The one false negative (Patient 13) is further evidence that the higher structures may occasionally be perfused after brain stem death. ${ }^{31}$

In two cases who died, no flow was seen in diastole. In both cases, the signals were obtained soon after deterioration and the Doppler-shift was small so that diastolic flow might have been obscured by arterial wall movement or the filter deleting instantaneous velocities of $<10 \mathrm{~cm} \mathrm{~s}^{-1}$. However, in the main trunk of the MCA, arterial wall movement is minimal as the vessel is insonated along its length, and instantaneous velocities $<10 \mathrm{~cm} \mathrm{~s}^{-1}$ are sometimes observed in practice. It should be noted that the values for velocity quoted in this paper are time averaged over the cardiac cycle. A sonagram with a time averaged velocity of $<10 \mathrm{~cm} \mathrm{~s}^{-1}$ may include instantaneous velocities of greater and less than $10 \mathrm{~cm} \mathrm{~s}^{-1}$.

An arteriogram was obtained in association with the Doppler findings in two cases; in one demonstra- ting absent intracranial flow and in the other confirming the presence of flow in both middle cerebral arteries. Previous authors $303135-39$ have described various arteriographic patterns in brain death: (1) absent intracranial flow with arrest of contrast in the neck, (2) arrest in the intradural parasellar part of the internal carotid, (3) arrest intracranially distal to the carotid siphon, or (4) arrest in the MCA trunk with stasis or reflux and shunting. Occasionally, a slow intracranial circulation is demonstrated with a delayed or absent venous phase. There is some suggestion that the point of arrest may be progressively more proximal as the time from the clinical diagnosis of brain death increases. ${ }^{37}{ }^{38}$ In our series, the characteristic signal with reverse flow throughout diastole or no diastolic flow was seen either soon after the initial insult, or very close to clinical or EEG deterioration during intensive care. In three cases, CPP had decreased acutely to $<5 \mathrm{~mm} \mathrm{Hg}$. This type of signal is probably equivalent to stasis or reflux in the proximal MCA on arteriography secondary to acutely uncontrollable intracranial hypertension. In several cases, a negative value for MCA velocity was obtained, whether velocity was analysed from the time averaged maximum frequency, as presented here or from the time averaged intensity weighted mean frequency (unpublished data) which is theoretically more likely to follow blood flow. ${ }^{40}$ This may represent an abnormal distribution of blood flow within the circle of Willis at an early stage of cerebral circulatory arrest or may simply be due to the error of the method. In several children, no signal was obtainable at a later stage, probably corresponding to an arteriographic pattern of arrest of contrast in the neck. It is important to emphasise that the demonstration of no Doppler signal without prior demonstration of reverse flow throughout diastole should be interpreted very cautiously, as the inexperienced may find difficulty in obtaining signals.

Non filling at arteriography has been associated with evidence of raised ICP in most cases, and if measured directly the ICP has usually been equal to systolic or mean arterial pressure. ${ }^{39}$ Holzman $^{41}$ suggested that this might not be the only factor, however, as in his series several children with no flow had a CPP of more than zero. ICP was measured with a subdural screw, as it was in the child in this series in whom CPP was not $<5 \mathrm{~mm} \mathrm{Hg}$ when the reverse flow signal was first seen. In the two children in whom ICP was measured using an intraventricular cannula ${ }^{42}$ (and in one where a subdural screw was used), CPP was zero when the reverse flow signal was seen. Because the swollen brain may obstruct the holes, the subdural screw may fail at low cerebral perfusion pressure, when measurement of ICP is most important. The intraventricular pressure monitor is 
therefore to be preferred.

The transcranial Doppler technique is simple and may be performed at the bedside as part of the monitoring of the unconscious patient. It may be especially useful immediately after a cerebral insult, as if reverse flow is observed throughout diastole in the middle cerebral artery, brain death is almost certain. If the situation cannot be rectified quickly, prolonged neurological intensive care is not indicated. If the reverse flow signal is seen during the subsequent course of the illness, this indicates that the patient has become brain dead and drugs which might preclude the clinical diagnosis should be withdrawn. The technique may also be useful in research, in defining the time of the insult in unconscious patients who deteriorate secondarily, and also in excluding those who would certainly not benefit from clinical trials of treatment. Demonstration of non-filling of the cerebral circulation is not a substitute for the clinical diagnosis of brain death, but an early indication of irreversible damage should be of benefit to all who are concerned with the intensive care of the unconscious patient.

We are very grateful to the following for support: the British Heart Foundation and the Peak Trust (FJK), the Coronary Artery Disease Research Association (TSP) and the Spastics Society (SDL and MCK). The Handicapped Children's Aid Committee provided some of the Doppler ultrasound equipment. We should like to thank our colleagues who allowed us to examine their patients, and Mrs D Patterson who prepared the manuscript.

\section{References}

1 A definition of irreversible coma. Report of the ad hoc committee of the Harvard Medical School to examine the definition of brain death. JAMA 1968;205:85-8.

2 The President's Commission for the study of ethical problems in medicine and biomedical and behavioural research. Defining death: medical, legal and ethical issues in the determination of death. Washington DC: US Government Printing Office, 1981.

3 Diagnosis of brain death. Statement issued by the honorary secretary of the Conference of Medical Royal Colleges and their Faculties in the United Kingdom on 11 October 1976. Br Med J 1976;2:1187-8.

4 Mohandas A, Chou SN. Brain death. A clinical and pathological study. $J$ Neurosurg $197 \mathrm{i} ; 35: 211-8$.

5 Allen N, Burkholder J. Clinical criteria of brain death. Ann N Y Acad Sci 1978;315:70-96.

6 Drake B, Ashwal S, Schneider S. Determination of cerebral death in the pediatric intensive care unit. Pediatrics 1986;78:107-12.

7 Rowland TW, Donnelly JH, Jackson AH, Jamroz SB. Brain death in the pediatric intensive care unit. Am J Dis Child 1983;137:547-50.

8 Crone RK. Brain death. Editorial. Am J Dis Child 1983;137:545-6.

9 Bruce DA, Raphaely RC, Goldberg AI, Zimmerman RA, Bilaniuk LT, Schut L, Kuhl DE. Pathophysiology, treatment and outcome following severe head injury in children. Child's Brain 1979;5:174-91.

10 Conn AW, Edmonds JF, Barker GA. Cerebral resuscitation in near drowning. Pediatr Clin North Am 1979;26:691-701.

11 Shaywitz BA, Rothstein P, Venes JL. Monitoring and management of increased intracranial pressure in Reye Syndrome: results in 29 children. Pediatrics 1980;66:198-204.

12 Aaslid R, Markwalder T-M, Nornes H. Non invasive transcranial Doppler ultrasound recording of flow velocity in basal cerebral arteries. J Neurosurg 1982;57:769-74.

13 Gillard JH, Kirkham FJ, Levin SD, Neville BGR, Gosling RG. Anatomical validation of middle cerebral artery position as identified by transcranial pulsed Doppler ultrasound. J Neurol Neurosurg Psychiatry 1986;49:1025-9.

14 Padayachee TS, Kirkham FJ, Lesi RR, Gillard JH, Hutchinson MCE, Gosling RG. Transcranial measurement of blood velocities in the basal cerebral arteries using pulsed Doppler ultrasound: a method of assessing the circle of Willis. Ultrasound Med Biol 1986;12:5-14.

15 Kirkham FJ, Padayachee TS, Parsons S, Seargeant LS, House FR, Gosling RG. Transcranial measurement of blood velocities in the basal cerebral arteries using pulsed Doppler ultrasound: velocity as an index of flow. Ultrasound Med Biol 1986;12:15-21.

16 Yoneda S, Nishimoto A, Nukada T, Kuriyama Y, Katsurada K, Abe H. To-and-fro movement and external escape of carotid arterial blood in brain death cases. A Doppler ultrasonic study. Stroke 1974;5:707-13.

17 Despland PA, de Crousaz G. L'apport de l'ultrasonographie Doppler au diagnostic de la mort cerebrale. Schweiz Med Wschr 1974;104:1454-9.

18 Kreutzer EW, Rutherford RB, Lehman RAW. Diagnosis of brain death by common carotid artery velocity waveform anal- $\bar{Q}$ ysis. Arch Neurol 1982;39:136-9.

19 Lewis RR, Padayachee TS, Beasley MG, Keen H, Gosling RG. Investigation of brain death with Doppler shift ultrasound. $J R$ Soc Med 1983;76:308-10.

20 Budingen HJ, Von Reutern G-M. Atraumatische vorfelddiagnostik des hirntodes mit der Doppler-sonographie. Deu-O tsche med Wschr 1979;104:1347-51.

21 McMenamin JB, Volpe JJ. Doppler ultrasonography in the deter mination of neonatal brain death. Ann Neurol 1983;14:302-7.?

22 Maynard DE, Jenkinson JL. The cerebral function analysing monitor. Initial clinical experience, application and further development. Anaesthesia 1984;39:678-90.

23 Eyre JA, Oozeer RC, Wilkinson AR. Diagnosis of neonatal seizure by continuous recording and rapid analysis of the electroencephalogram. Arch Dis Child 1983;58:785-90.

24 Pampiglione G, Harden A. Resuscitation after cardiac arrest. Lancet 1968;ii:1261-4.

25 Bennett DR. The EEG in determination of brain death. Ann NY Acad Sci 1978;315:110-20.

26 Powner DJ. Drug-associated isoelectric EEGs. A hazard in brain death certification. JAMA 1976;236:1123.

27 Spudlis EV, Penry JK, Link AS. Paradoxical contributions of EEG during protracted dying. Arch Neurol 1984;41:153-6.

28 Ashwal S, Schneider S. Failure of electroencephalography to diagnose brain death in comatose children. Ann Neurol 1979;6:512-7.

29 Smith AJK, Walker AE. Cerebral blood flow and brain metabolism as indicators of cerebral death. Johns Hopkins Med J 1973;133:107-19.

30 Rosenklint A, Jorgensen PB. Evaluation of angiographic methods in the diagnosis of brain death. Correlation with local and systemic arterial pressure and intracranial pressure. Neuroradiology 1974;7:215-9.

31 Grietz T, Gordon E, Kolmodin G, Widen L. Aortocranial and carotid angiography in determination of brain death. $\mathrm{Neu}$ roradiology 1973;5:13-9.

32 Jorgensen PB, Karle A, Rosenklint A. Changes in blood pressure 
and cardiac rhythm by arterial contrast injection. Neuroradiology 1973;5:215-9.

33 Korein J, Braunstein P, Kricheff I, Lieberman A, Chase N. Radioisotope bolus technique as a test to detect circulatory deficit associated with cerebral death. Circulation 1975;51:924-39.

34 Goodman JM, Heck LL. Confirmation of brain death at bedside by isotope angiography. $J A M A$ 1977;238:966-8.

35 Pribam HFW. Angiographic appearances in acute intracranial hypertension. Neurology 1961;11:10-21.

36 Riishede J, Ethelberg S. Angiographic changes in sudden and severe herniation of brain stem through tentorial incisure. Arch Neurol Psychiatr 1953;70:399-409.

37 Bucheler E, Kaufer C, Dux A. Zerebrale angiographie zur bestimmung des hirntodes. Fortshr Geb Roentgenstr Nuklearmed
1970;113:278-96.

38 Heiskanen $O$. Cerebral circulatory arrest caused by acute increase of intracranial pressure. Acta Neurol Scand 1964;40:suppl 7.

39 Langfitt TW, Kassell NF. Non-filling of cerebral vessels during angiography: correlation with intracranial pressure. Acta Neurochir 1966;14:96-104.

40 Evans DH. Some aspects of the relationship between instantaneous volumetric blood flow and continuous wave Doppler ultrasound recordings. Ultrasound Med Biol 1982;8:605-23.

41 Holzman BH, Curless RG, Sfakianakis GN, Ajmone-Marsan C, Montes JE. Radionuclide cerebral perfusion scintigraphy in determination of brain death in children. Neurology 1983;33:1027-31.

42 McWilliam RC, Stephenson JBP. Rapid bedside technique for intracranial pressure monitoring. Lancet 1984;ii:73-5. 